\title{
Systematic Review: Individuals’ Goals for Surrogate Decision-Making
}

\author{
Brenna Kelly, JD, MPH, Annette Rid, MD, ${ }^{* *}$ and David Wendler, PhD
}

OBJECTIVES: To determine to what extent current practice promotes the goals of individuals who did not designate a surrogate while competent with respect to decisionmaking during periods of decisional incapacity.

DESIGN: Systematic literature search for studies published in English and listed in PubMed, Scopus, Embase, CINAHL, or PsycINFO. Studies were eligible if they provided quantitative or qualitative empirical data on how adults want treatment decisions to be made for them during periods of incapacity.

SETTING: Primarily United States, with six other countries.

PARTICIPANTS: Fourteen qualitative articles, representing 11 distinct data sets, and 26 quantitative articles, representing 25 distinct data sets, providing data on the views of 22,828 individuals, met the inclusion criteria. Most of the respondents were elderly or seriously ill.

MEASUREMENTS: Quantitative surveys and qualitative interview studies assessing individuals' goals.

RESULTS: The majority wanted close family members to act as their surrogate. The most common reason for preferring family members was the belief that they know which treatments the patient would want. Individuals also wanted to reduce the burden on their families. There was significant variation in the extent to which respondents wanted their surrogates to have leeway when making treatment decisions.

CONCLUSION: Individuals have three primary goals with respect to making treatment decisions for them during periods of incapacity: involve their family, treat them consistently with their own treatment preferences, and reduce the burden on their family. Unfortunately, prior systematic reviews have found that family members often are not able to determine which treatment patients want, and family members frequently experience substantial distress when

From the "University of Michigan Law School, Ann Arbor, Michigan; "Institute of Biomedical Ethics, University of Zurich, Zurich, Switzerland; and ${ }^{*}$ Department of Bioethics, National Institutes of Health Clinical Center, Bethesda, Maryland.

Address correspondence to David Wendler, Department of Bioethics, NIH Clinical Center, Building 10, Room 1C118, Bethesda, MD 20892. E-mail: dwendler@nih.gov

DOI: 10.1111/j.1532-5415.2012.03937.x acting as surrogates. These findings suggest that current practice frequently fails to promote individuals' primary goals for treatment decision-making. Future research should evaluate ways to better promote individuals' goals. In the meantime, clinicians should be aware of these findings and should encourage patients to document their own goals, including their treatment preferences and their preferences regarding how they want decisions to be made for them during periods of decisional incapacity. J Am Geriatr Soc 60:884-895, 2012.

Key words: surrogate; end of life; decision-making; incapacity; goals; preferences; values

$\mathbf{R}$ espect for autonomy implies that individuals should be allowed to make their own treatment decisions, typically in consultation with a clinician. Yet many people, including the majority of those at the end of life, are not able to make decisions. ${ }^{1-3}$ Moreover, the majority of individuals do not complete an advance directive or otherwise leave clear instructions for how they want to be treated during periods of decisional incapacity. ${ }^{4}$

Designated surrogates make decisions for incapacitated individuals who completed a durable power of attorney while competent. For incapacitated individuals who did not designate a surrogate while competent, the next of kin makes treatment decisions. Surrogates, whether patient designated or next of kin, are instructed to make decisions based on the substituted judgment standard, making the treatment decision they think the individual would have made if he or she were capable. ${ }^{5,6}$ Proponents argue that this approach extends individual autonomy by allowing individuals' preferences and values to guide how they are treated, even when they are not able to make their own decisions.

No systematic analyses have attempted to identify individuals' goals with respect to treatment decision-making during periods of incapacity. As a result, it is unclear to what extent current practice promotes individuals' goals. In the absence of an advance directive, how do individuals want treatment decisions to be made for them? Does current practice of relying on the next of kin, and 
instructing them to use the substituted judgment standard, promote individuals' goals? To assess these questions, a systematic review of the empirical literature was conducted to evaluate how individuals want treatment decisions to be made for them during periods of decisional incapacity.

\section{METHODS}

\section{Data Sources and Searches}

PubMed, Scopus, Embase, CINAHL, and PsycINFO were searched for studies published in English that provide quantitative or qualitative empirical data on how adults want treatment decisions to be made for them during periods of decisional incapacity. Studies were eligible if they were indexed before August 2, 2010. The search combined Medical Subject Headings in three inclusion categories: end-of-life care, attitudes, and family or surrogate. (See Appendix for the specific terms used.)

\section{Study Selection}

The systematic search identified 6,551 articles, and the authors identified seven additional articles. (See Figure 1 for the selection process.) Two authors independently reviewed the titles of the articles and categorized them as ineligible, of unclear eligibility, possibly eligible, or probably eligible. Categorization was performed while blinded to the articles' authors and affiliations. Articles were judged to be ineligible only if the reviewer was confident, based on the title, that the article would not satisfy the inclusion criteria of providing quantitative or qualitative empirical data by surveying adults regarding how they want treatment decisions to be made for them during periods of decisional incapacity. Titles that both authors agreed clearly failed to satisfy these criteria were eliminated, leaving 273 potentially eligible studies.

The same two authors read the abstracts (or first pages of articles without abstracts) of the 273 articles and

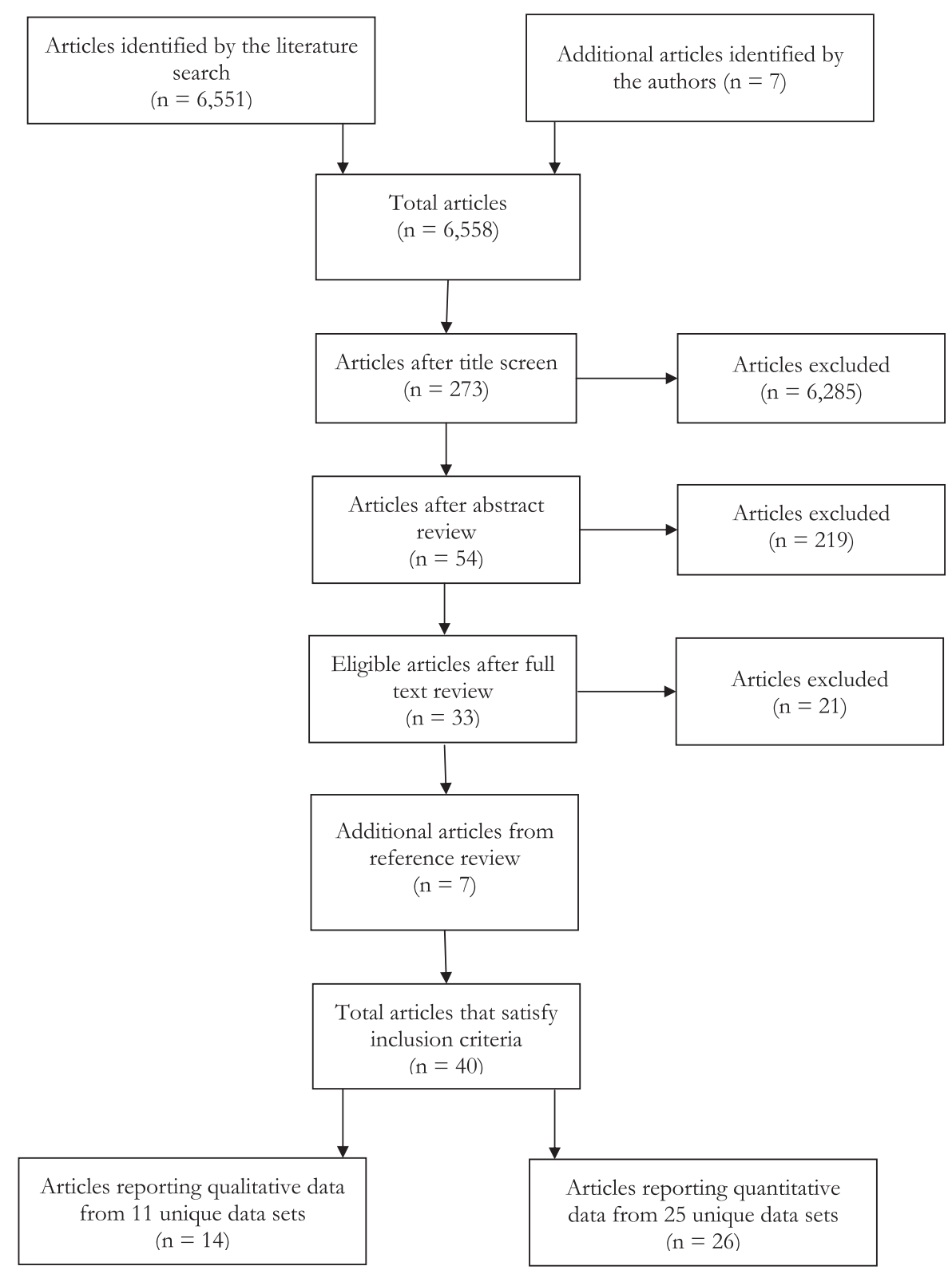

Figure 1. Literature search and selection. 
ranked them as ineligible, of unclear eligibility, or likely eligible. This process identified 54 articles as being of unclear eligibility or likely eligible. Both authors independently read the full text of these 54 articles and identified 33 articles that satisfied the inclusion criteria. Review of the references of the 33 eligible articles yielded four additional eligible articles. The references of these four articles were reviewed, yielding no additional eligible articles.

To determine whether the systematic search missed any eligible articles, the two authors evaluated the references of a related systematic review, which evaluated the effect of making treatment decisions on surrogates. ${ }^{7}$ This review identified three additional eligible articles. Review of the references of these three articles yielded no additional eligible articles. Finally, five researchers in the field were contacted to determine whether they were aware of any eligible articles that had been missed, yielding no additional eligible articles. Thus, in total, 40 articles met the inclusion criteria.

\section{Data Extraction and Quality Assessment}

Two authors independently read the 40 eligible articles and extracted data on study location, number and type of respondents, response rate, methods, main findings, and limitations. When the extracted data from two different articles appeared to be related, the corresponding authors were contacted to determine whether the two articles were based on the same data set.

Two authors assessed the methodological strength of the eligible articles by giving them one point for each of 12 criteria that they satisfied. (See Table 1 for specific criteria.) When a criterion was not mentioned in the article, it was regarded as not satisfied. The final strength score is intended to reflect the extent to which the articles provide valid data relevant to the inclusion criteria used in the present review.

The quantitative articles used a range of different instruments, making it impossible to conduct formal statistical analyses on the aggregate results. The reviewed data are thus presented as a narrative summary. ${ }^{8}$

\section{RESULTS}

\section{Identified Studies}

The literature search identified 40 articles published in English before August 2, 2010, that met the inclusion criteria. ${ }^{9-48}$ These articles provided data from 36 distinct data sets. The number of individuals evaluated in the articles ranged from 12 to 8,000 , for a total of 22,828 individuals evaluated. Twenty articles reported the views of elderly individuals, typically aged 65 and older, ${ }^{14,15,17,18,20-24,26,27,29-31,33,36-38,42,44}$ nine reported the views of terminally or seriously ill patients. ${ }^{14,16,19,28,34,37,42,45,46}$ Ten articles focused on the views of particular patient or ethnic groups. $9,25,29,30,32,35,40,41,47,48$ Only six articles surveyed a larger cross-section of a given population. ${ }^{10-13,39,43}$

The articles focused on whom individuals wanted to be their surrogate if they could no longer make decisions for themselves. Thirteen articles also evaluated why individuals preferred a particular surrogate; nine evaluated

\section{Table 1. Strength Criteria (Adapted from Ref. 7)}

\section{Quantitative studies}

For each of the following criteria satisfied, a point was given

1. Trained interviewers

2. Interviewers independent of the care team

3. Selected a representative sample

4. Performed measures to ensure the reliability of the data

5. Performed measures to ensure the validity of the data

6 . Evaluated why respondents selected a particular person or process for end-of-life decision-making

7. Reported respondents' sociodemographic characteristics

8. Response rate exceeded $50 \%$

9. Reported the raw number or percentage of respondents for each reported theme or result

10. Specified the number of participants needed to reach statistical significance

11. Reached the specified number of participants

12. Statistical analysis of the findings

Qualitative studies

For each of the following criteria satisfied, a point was given

1. Trained interviewers

2. Interviewers independent of the care team

3. Selected a representative sample

4. Performed measures to ensure the reliability of the data

5. Performed measures to ensure the validity of the data

6 . Evaluated why respondents selected a particular person or process for end-of-life decision-making

7. Reported respondents' sociodemographic characteristics

8. Response rate exceeded $50 \%$

9. Reported the raw number or percentage of respondents for each reported theme or result

10. Reported theme saturation

11. Recorded verbatim answers

12. Coded findings in a blind and independent manner

how much leeway individuals thought that their surrogate should have when making treatment decisions.

The first article was published in 1987; 22 articles were published in 2000 or later. Twenty-nine of the articles surveyed individuals in the United States; three surveyed individuals in Canada; two each in France and Japan; one each in Sweden, Australia, and Singapore; and one in Japan and the United States. Twenty-six articles reported quantitative data from 25 distinct data sets, and 14 reported qualitative data from 11 unique data sets (Tables 2 and 3). The quantitative articles used a range of instruments. Most of the qualitative articles used semistructured interviews. The qualitative articles reported data using direct quotations, as well as general descriptors of the results, such as a lot, some, and a little.

\section{Who Individuals Want to Make Decisions for Them}

The identified articles indicated that the vast majority of respondents wanted close family members to make treatment decisions for them during periods of decisional incapacity (Tables 2 and 3). In six articles, most respondents preferred their spouse to make decisions. ${ }^{11,13,18,36,37,44}$ Twelve articles reported that most respondents preferred that their adult children act as surrogates. ${ }^{14,15,20-24,26,27,31,37,42}$ In one of these articles, individuals preferred their adult children as decision-makers because they assumed that their spouses would predecease them. ${ }^{42} \mathrm{~A}$ minority of 


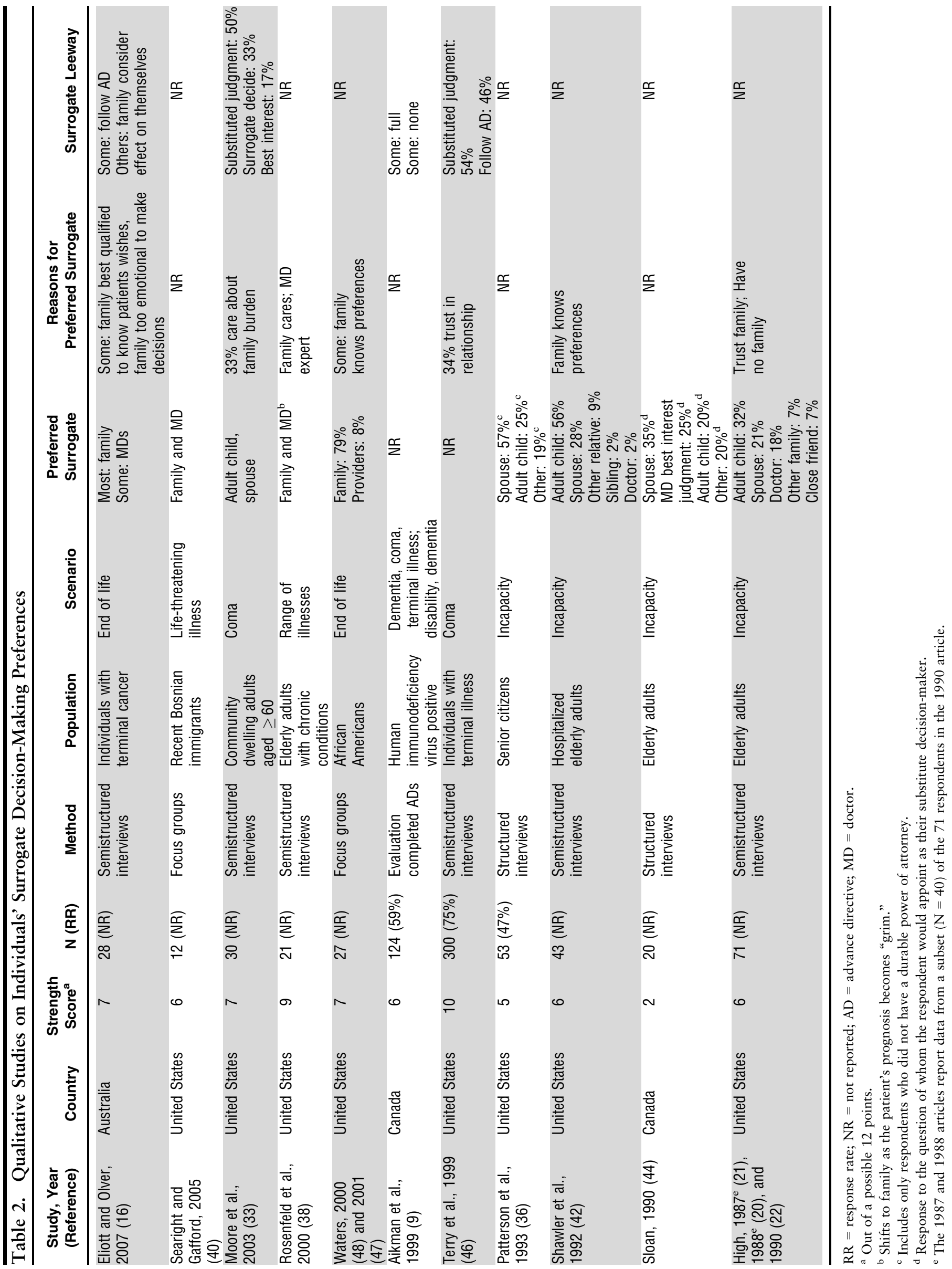




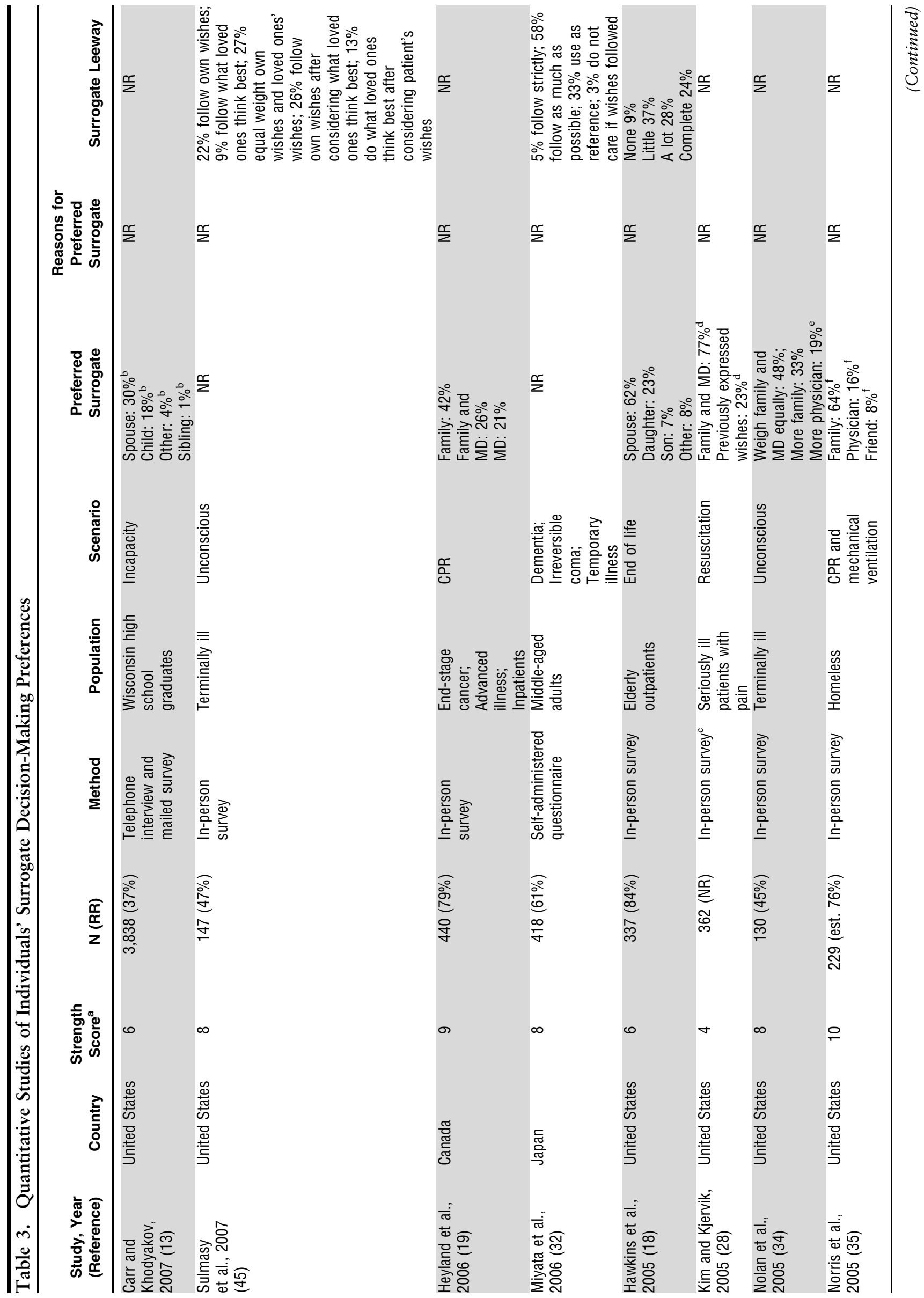




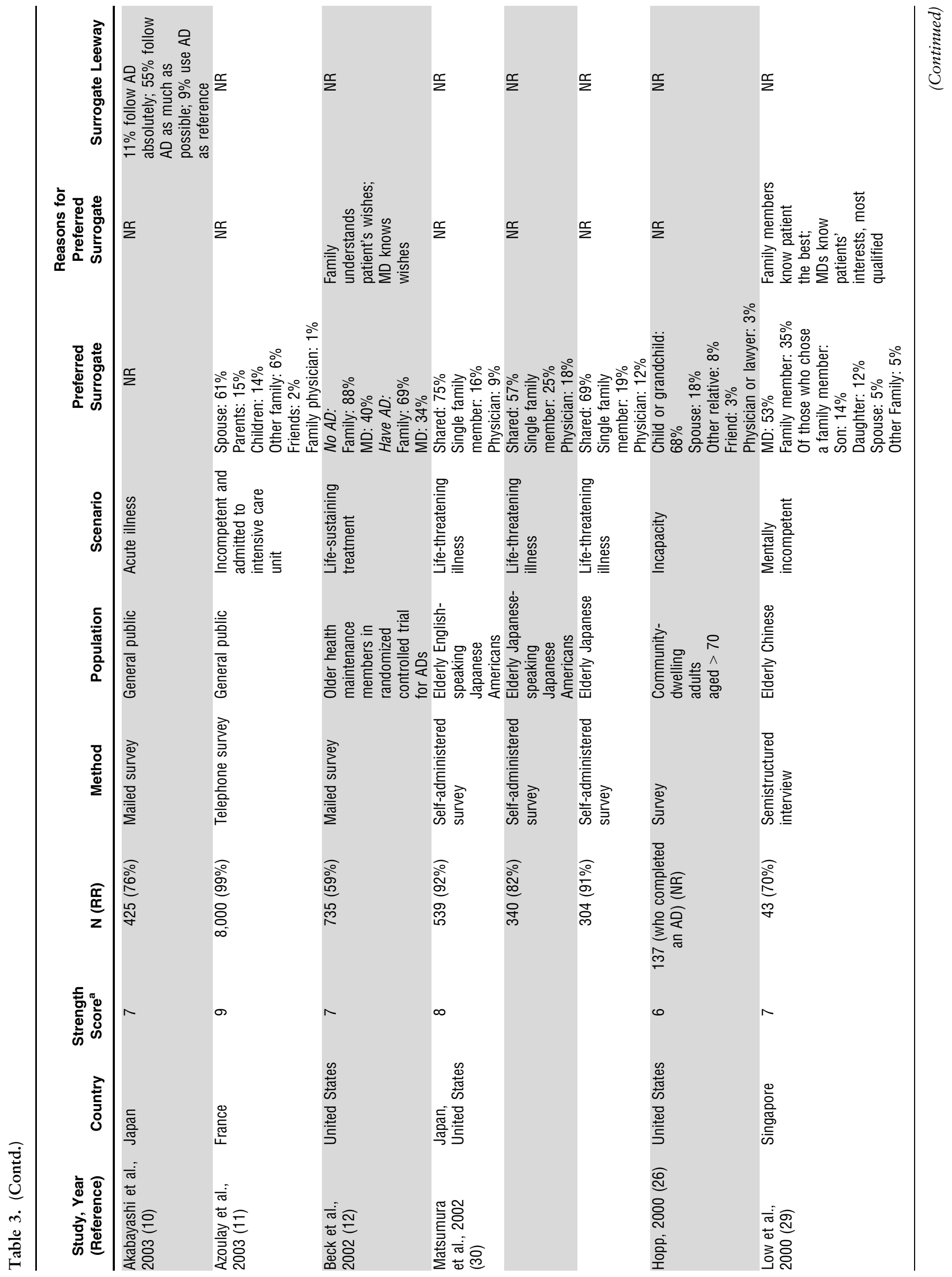




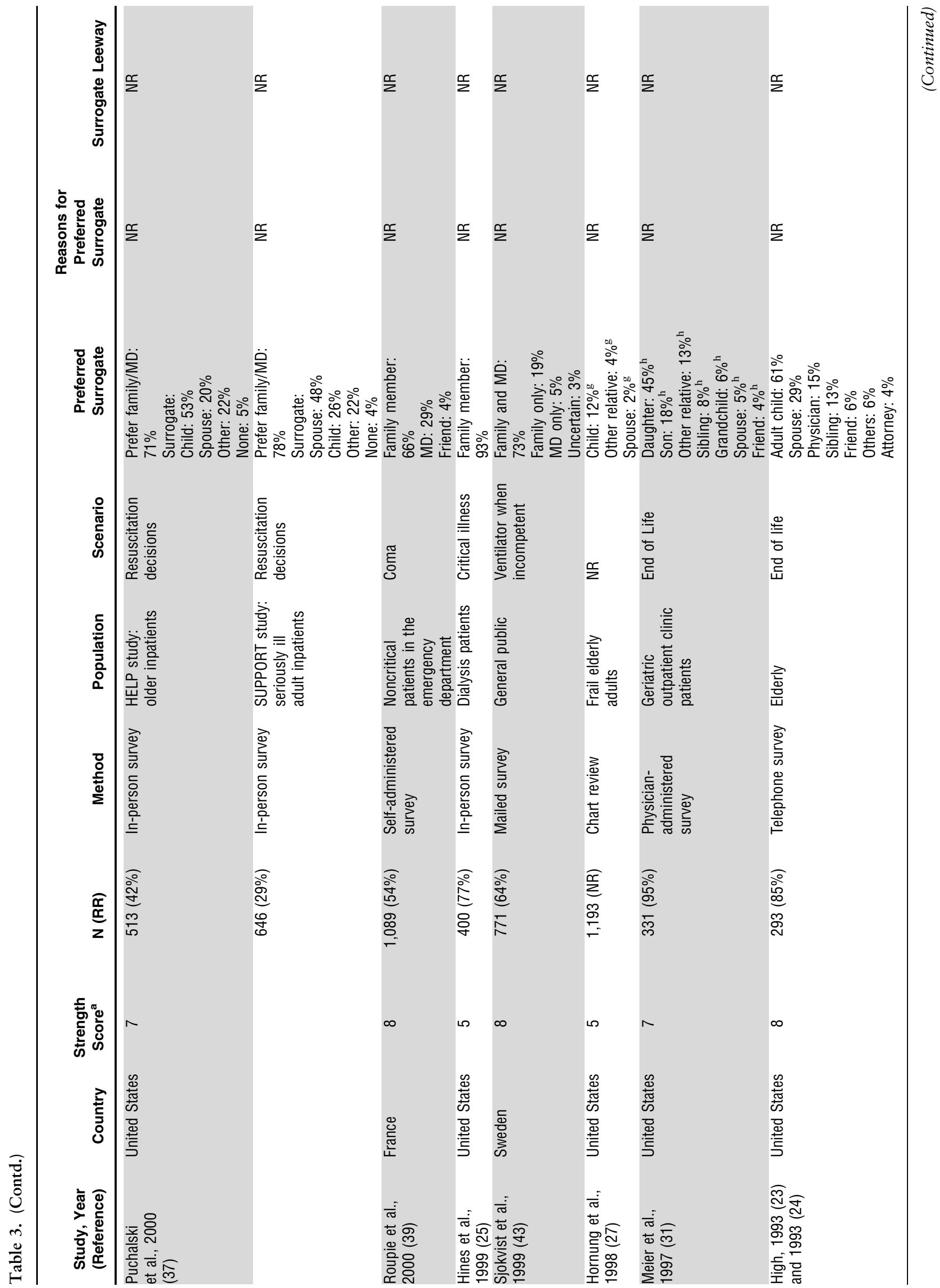




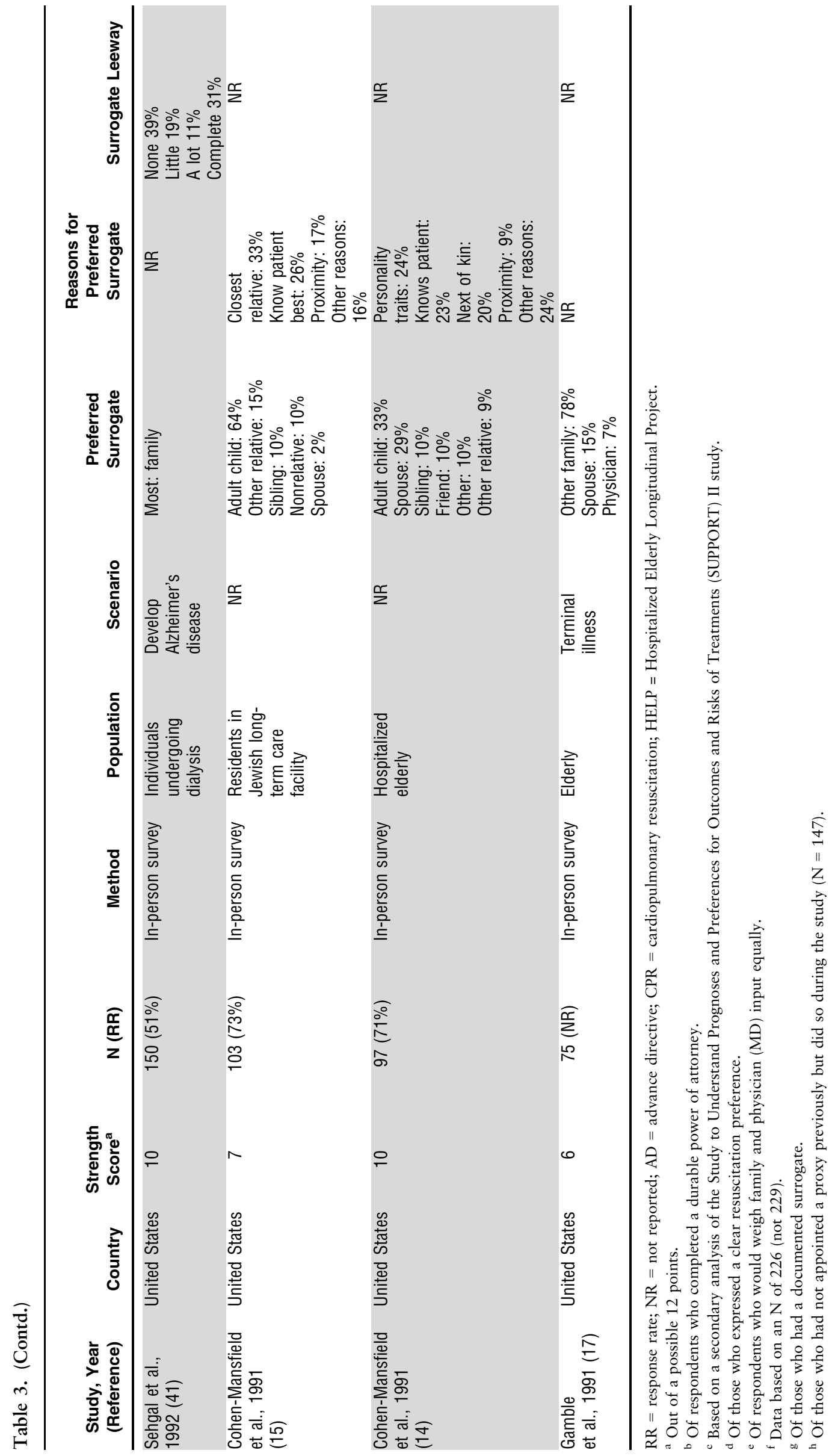


respondents in the various articles preferred that a nonfamily member and nonphysician make treatment decisions. ${ }^{11,14,15,20-24,26,31,35,39}$ This preference sometimes reflected the fact that the respondent did not have any immediate family. ${ }^{20-22,26}$ In other cases, individuals did not want their family members to be involved in making decisions because of disagreements or conflicts they had with their family. 9,46

Fifteen articles, reporting the findings of 12 data sets, found that the majority of respondents wanted their family members to make decisions together. ${ }^{11,18-}$ $22,28,30,34,38,42,43,45,47,48$ One respondent identified as his preferred decision-maker: "My wife, my son, and daughter. I am a firm believer that these are joint decisions." ${ }^{20}$ Another stated that decisions should be made by "My three daughters together.... They'd make them together. They'd just stick together." ${ }^{42}$ Most respondents wanted their family members to consult with their clinicians during the decision-making process.

\section{Reasons for Surrogate Preference}

Fourteen articles, reporting the findings of 11 data sets, evaluated why respondents preferred a particular surrogate. $^{12,14-16,20-22,29,33,38,42,46,47,48}$ Eleven of these articles found that most individuals wanted a family member to be their surrogate because the respondent assumed that family members would know their treatment preferences. ${ }^{12,16,20-}$ $22,29,33,42,4647,48$ For example, one respondent explained the preference for her daughter on the grounds that "My daughter would choose what I would do in the situation." ${ }^{46}$ In some cases, respondents' confidence in their family's ability to determine their own treatment preferences was based on previous discussions between the patient and family member: "I have talked to my son and daughter. In all probability I'll predecease them, so I thought that was good enough." 22

Seventeen articles provided quantitative data regarding whether respondents had any discussion with someone else regarding end-of-life decision-making; none quantified the frequency, length, or depth of discussion. 14,15,17,19,20,2226,30-32,41,42,45,46 Of these 17 articles, 11 found end-of-life discussion rates of lower than $50 \% .{ }^{14,15,17,19,26,30,32,41,42,45,46}$ An additional five articles found rates lower than $70 \% .{ }^{20,22-25}$ Only one reported discussion rates higher than $70 \%{ }^{31}$

Ten articles found that respondents preferred family members as surrogates based on trust. ${ }^{14,20-22,33,38,42,46-48}$ Some respondents trusted their family members to implement their wishes. For example, one respondent stated: "You need someone you have confidence in to carry out your wishes." 47 Others trusted their family members to protect their interests: "My daughter would have my best interest at heart." 46

\section{How Much Leeway Do Individuals Want to Grant Their Surrogates}

Nine articles evaluated how much leeway individuals thought their surrogates should have when making treatment decisions for them. ${ }^{9,10,16,18,32,33,41,45,46}$ One of these articles explicitly defined "leeway" as "freedom to do what they think is best for you." ${ }^{41}$ Another used the term "leeway" without defining it. ${ }^{18}$ Two articles incorporated some explanation of leeway in the question. ${ }^{9,10}$ For example, one asked respondents: "How much leeway do you want to give your proxies in interpreting your wishes?" The remaining five articles evaluated the concept without using the term "leeway."16,32,33,45,46 For example, one article reported respondents' views regarding "to what extent their proxy should respect their treatment preferences." 32

These nine articles found that the preferred amount of leeway varied widely. One quantitative article reported that $58 \%$ of respondents wanted their surrogates to have none or a little leeway, whereas $42 \%$ wanted their surrogates to have a lot or complete leeway. ${ }^{41}$ Another quantitative article found that $63 \%$ of respondents wanted their surrogates to follow their advance directives strictly or as much as possible, whereas $33 \%$ wanted their surrogates to use their advance directives as a reference only, and $3 \%$ did not care if their wishes were followed. ${ }^{32}$ The qualitative articles, which found that some respondents "granted permission to proxies to freely interpret their written preferences," whereas others insisted that their surrogates "follow their instructions precisely," supported these findings. ${ }^{9}$

The reasons why respondents wanted their surrogates to have leeway or not also varied. Many respondents who wanted their wishes followed simply wanted to have some treatments and avoid others. Others regarded the following of their wishes as a way to avoid burdening their family., 90,18 One respondent stated: "follow my directions to the $\mathrm{T}$, because I do not want anyone to feel guilty that they made the wrong decision." 9 Other respondents felt that giving their surrogate leeway would allow the surrogate to make treatment decisions that better promoted the patient's interests. $9,10,18$

\section{Study Strength}

The median strength score of the identified articles was 7 out of 12 (range 2-10); 33 of the 40 articles scored 8 points or less. Several of the deficiencies are of particular importance. For example, 15 articles did not report a response rate, and five had response rates below $50 \%$ (Tables 1-3).

\section{Limitations}

The present findings are subject to at least five important limitations. First, the strength of the identified articles was low, with a median strength score of 7 out of 12 . Second, only 13 articles, reporting the findings of 10 data sets, asked respondents why they preferred a particular surrogate or a particular method for making treatment decisions. Third, the studies were conducted in a range of groups in different countries around the world. Thus, the present data are not robust enough to detect significant differences in views between groups and in different countries. Similarly, the wide range of survey instruments used precludes subgroup analyses of the data. Fourth, the nine articles that assessed leeway relied on different understandings of the concept. Some understood leeway as flexibility 
in interpreting the individual's stated preferences; others understood leeway as the flexibility to make decisions that were not consistent with the individual's stated preferences. Fifth, most respondents were older, very ill, or both. Although this group of individuals represents those for whom decisional incapacity is most likely, it may have failed to detect differences based on age or generational cohort.

\section{DISCUSSION}

Systematic review of the published data on more than 22,000 respondents from 36 unique data sets suggests that individuals have three primary goals with respect to how treatment decisions are made for them during periods of decisional incapacity. First, the vast majority of individuals want their close family members to make treatment decisions, typically in consultation with the individual's doctors. Second, individuals want to be treated consistently with their own preferences and values; most believe that relying on their family to make decisions will promote this goal. Third, many individuals want to minimize the burden on their families.

In the absence of an advance directive, current practice relies on the next of kin to make treatment decisions for incapacitated individuals. Yet prior systematic reviews have found that family members often do not know patients' treatment preferences, ${ }^{49}$ and family members often experience substantial burden when acting as surrogates. ${ }^{7}$ The present findings, when combined with those of these prior systematic reviews, suggest that current practice is promoting only one of individuals' three primary goals with respect to decision-making during periods of incapacity. Current practice realizes individuals' primary goal that close family members make treatment decisions for them. Yet the way families currently make decisions likely undermines individuals' two other primary goals: receiving treatments they want and avoiding burden on their families.

\section{Implications for Future Research}

Future research should assess whether modifications to current practice, or alternative approaches, might better promote individuals' goals. In particular, future research will be needed to assess whether it is possible to involve family members in the decision-making process in ways that reduce the burdens on them and also increase the chances that individuals are treated consistent with their own preferences and values. ${ }^{50}$

One approach that has gained considerable support is shared decision-making, which involves family members and clinicians making decisions together. ${ }^{51,52}$ Clinicians may be able to help clarify the circumstances and options and take on some responsibility for the ultimate decision. Unfortunately, data suggest that clinicians may be less able than family members to predict their patients' treatment preferences. ${ }^{53-55}$ Thus, greater involvement of clinicians in the decision-making process may help to promote individuals' goal of reducing the burden on their family ${ }^{7}$ while undermining their goal of being treated consistently with their own preferences.
A second approach that has been proposed is to provide family members with predictions for what treatment course the individual would want based on the individuals' sociodemographic characteristics. ${ }^{56,57}$ Future research will be needed to evaluate whether this approach increases the chances that individuals are treated consistently with their preferences; whether it reduces the burden on their families; and what patients think about this approach.

In addition to evaluating ways to promote all three of individuals' primary goals, future research should consider how individuals prioritize these goals. Do individuals care more about having their family involved in the decisionmaking process, about reducing the burden on their families, or about receiving the treatments they want? Answering this question will be especially important if future research fails to identify approaches that successfully promote all three goals.

\section{Implications for Clinical Practice}

What implications do the present findings have for clinical practice? First, clinicians should be aware that individuals often assume that their family members know their treatment preferences. Given that this often is not the case, ${ }^{49}$ clinicians should encourage individuals to discuss their preferences with their designated surrogates and document them using an advance directive. These steps may increase the chances that at least individuals who have specific treatment preferences are treated consistent with them. ${ }^{3}$ In addition, the presence of an advance directive often reduces the burden on surrogate decision-makers. ${ }^{7}$

Second, in addition to specific treatment preferences, clinicians should encourage individuals to use their advance directives to document any preferences they have regarding how treatment decisions are made for them. To what extent is the individual concerned primarily with the treatments they receive versus who makes decisions for them versus the effect on their families? This information will help surrogate decision-makers to better respect individuals' preferences.

Third, some commentators have argued that current practice inappropriately directs surrogates to make the decision they think the individual would have made if capable. $^{58}$ These commentators argue that surrogates should instead have leeway to take into account considerations other than the individual's treatment preferences, including the effect of the treatment options on the family. Although the present findings suggest that many individuals want their surrogates to have substantial leeway, many others do not. In addition, those who want their surrogates to have substantial leeway often assume that this approach is more likely to result in their receiving the treatments they want. In contrast, some respondents who are concerned about the effect on their families want their advance directives to be followed strictly because they assume that this approach will reduce the burdens on their family.

These findings suggest that it is not possible to develop un unequivocal recommendation regarding how much leeway surrogates should have. In addition, simply asking individuals to specify the amount of leeway they want their surrogates to have may lead to confusion regarding 
the individual's ultimate goals. To address this concern, individuals could be encouraged to document their most important goal with respect to making treatment decisions for them during periods of decisional incapacity. Individual also might document how much leeway they want their surrogates to have and the reasons for granting their surrogates leeway or not.

\section{CONCLUSION}

Review of the published literature suggests that individuals have three primary goals with respect to treatment decision-making during periods of decisional incapacity: involve their family, being treated consistently with their own preferences and values, and minimize the burden on their family. In the absence of an advance directive, current practice attempts to promote individuals' goals by relying on family members to make treatment decisions using the substituted judgment standard. Yet previous reviews show that family members often do not know the individual's treatment preferences ${ }^{49}$ and often experience substantial burden when acting as surrogates. ${ }^{7}$ Clinicians should be aware of these findings and encourage individuals to discuss and document their own goals, including any specific treatment preferences and their preferences regarding how they want decisions to be made for them. Future research should consider whether modifications to current practice or alternative approaches might better promote all three of individuals' primary goals with respect to decision-making during periods of incapacity.

\section{ACKNOWLEDGMENTS}

Thanks to Karen Smith for extensive assistance with the literature search.

Conflict of Interest: The editor in chief has reviewed the conflict of interest checklist provided by the authors and has determined that the authors have no financial or any other kind of personal conflicts with this paper.

The present work was completed as part of the authors' official duties as employees of the National Institutes of Health (NIH) Clinical Center. Annette Rid gratefully acknowledges funding from the Swiss National Science Foundation.

Author Contributions: AR and DW conceived of the project. BK and DW collected the data. BK wrote the first draft. BK, AR, and DW edited the draft. DW provided supervision.

Sponsor's Role: The present project was funded by the Department of Bioethics, NIH Clinical Center. However, the NIH had no role in the design, methods, subject recruitment, data collections, analysis or preparation of the paper.

\section{REFERENCES}

1. Raymont V, Bingley W, Buchanan A et al. Prevalence of mental incapacity in medical inpatients and associated risk factors: Cross-sectional study. Lancet 2004;364:1421-1427.

2. Prendergast TJ, Claessens MT, Luce JM. A national survey of end-of-life care for critically ill patients. Am J Respir Crit Care Med 1998;158:1163-1167.

3. Silveira MJ, Kim SY, Langa KM. Advance directives and outcomes of surrogate decision making before death. N Engl J Med 2010;362:1211-1218.
4. Fagerlin A, Schneider CE. Enough. The failure of the living will. Hastings Cent Rep 2004;34:30-42.

5. Beauchamp TL, Childress JF. Principles of Biomedical Ethics, 6th Ed. New York: Oxford University Press, 2009.

6. Buchanan AE, Brock DW. Deciding for Others: The Ethics of Surrogate Decision Making. Cambridge, UK: Cambridge University Press, 1989.

7. Wendler D, Rid A. The effect on surrogates of making treatment decisions for others. Ann Intern Med 2011;154:336-346.

8. Dixon-Woods M, Agarwal S, Jones D et al. Synthesizing qualitative and quantitative evidence: A review of possible methods. J Health Serv Res Pol 2005;10:45-53.

9. Aikman PJ, Thiel EC, Martin DK et al. Proxy, health, and personal care preferences: Implications for end-of-life care. Camb Q Healthc Ethics 1999;8:200-210.

10. Akabayashi A, Slingsby BT, Kai I. Perspectives on advance directives in Japanese society: A population-based questionnaire survey. BMC Med Ethics 2003;4:E5.

11. Azoulay E, Pochard F, Chevret S et al. Opinions about surrogate designation: A population survey in France. Crit Care Med 2003;31:1711-1714.

12. Beck A, Brown J, Boles $\mathrm{M}$ et al. Completion of advance directives by older health maintenance organization members: The role of attitudes and beliefs regarding life-sustaining treatment. J Am Geriatr Soc 2002;50:300-306.

13. Carr D, Khodyakov D. Health care proxies: Whom do young old adults choose and why? J Health Soc Behav 2007;48:180-194.

14. Cohen-Mansfield JC, Droge JA, Billig N. The utilization of the durable power of attorney for health care among hospitalized elderly patients. J Am Geriatr Soc 1991;39:1174-1178.

15. Cohen-Mansfield J, Rabinovich BA, Lipson S et al. The decision to execute a durable power of attorney for health care and preferences regarding the utilization of life-sustaining treatments in nursing home residents. Arch Intern Med 1991;151:289-294.

16. Eliott J, Olver I. Autonomy and the family as (in)appropriate surrogates for DNR decisions: A qualitative analysis of dying cancer patients' talk. J Clin Ethics 2007;18:206-218.

17. Gamble ER, McDonald PJ, Lichstein PR. Knowledge, attitudes, and behavior of elderly persons regarding living wills. Arch Intern Med 1991;151:277-280.

18. Hawkins NA, Ditto PH, Danks JH et al. Micromanaging death: Process preferences, values, and goals in end-of-life medical decision making. Gerontologist 2005;45:107-117.

19. Heyland D, Frank C, Groll D et al. Understanding cardiopulmonary resuscitation decision making: Perspectives of seriously ill hospitalized patients and family members. Chest 2006;130:419-428.

20. High DM. All in the family: Extended autonomy and expectations in surrogate health care decision-making. Gerontologist 1988;28:46-50.

21. High DM, Turner HB. Surrogate decision-making: The elderly's familial expectations. Theor Med 1987;8:303-320.

22. High DM. Who will make health care decisions for me when I can't? J Aging Health 1990;2:291-309.

23. High DM. Advance directives and the elderly: A study of intervention strategies to increase use. Gerontologist 1993;33:342-349.

24. High DM. Why are elderly people not using advance directives? J Aging Health 1993;5:497-515.

25. Hines SC, Glover JJ, Holley JL et al. Dialysis patients' preferences for family-based advance care planning. Ann Intern Med 1999;130:825-828.

26. Hopp FP. Preferences for surrogate decision makers, informal communication, and advance directives among community-dwelling elders: Results from a national study. Gerontologist 2000;40:449-457.

27. Hornung CA, Eleazer GP, Strothers HS et al. Ethnicity and decision-makers in a group of frail older people. J Am Geriatr Soc 1998;46:280-286.

28. Kim SH, Kjervik D. Deferred decision making: Patients' reliance on family and physicians for CPR decisions in critical care. Nurs Ethics 2005;12:493 -506 .

29. Low JA, Ng WC, Yap KB et al. End-of-life issues: Preferences and choices of a group of elderly Chinese subjects attending a day care centre in Singapore. Ann Acad Med Singapore 2000;29:50-56.

30. Matsumura S, Bito S, Liu H et al. Acculturation of attitudes toward endof-life care. J Gen Intern Med 2002;17:531-539.

31. Meier DE, Gold G, Mertz K et al. Enhancement of proxy appointment for older persons: Physician counseling in the ambulatory setting. J Am Geriatr Soc 1996; $44: 37-43$

32. Miyata H, Shiraishi H, Kai I. Survey of the general public's attitudes toward advance directives in Japan: How to respect patients' preferences. BMC Med Ethics 2006;7:E11.

33. Moore CD, Sparr J, Sherman S et al. Surrogate decision-making: Judgment standard preferences of older adults. Soc Work Health Care $2003 ; 37: 1-16$ 
34. Nolan MT, Hughes M, Narendra DP et al. When patients lack capacity: The roles that patients with terminal diagnoses would choose for their physicians and loved ones in making medical decisions. J Pain Symptom Manage 2005;30:342-353.

35. Norris WM, Nielsen EL, Engelberg RA et al. Treatment preferences for resuscitation and critical care among homeless persons. Chest 2005;127:2180-2187.

36. Patterson SL, Baker M, Maeck JP. Durable powers of attorney: Issues of gender and health care decision-making. J Gerontol Soc Work 1993;21:161 -177 .

37. Puchalski CM, Zhong Z, Jacobs MM et al. Patients who want their family and physician to make resuscitation decisions for them: Observations from SUPPORT and HELP. J Am Geriatr Soc 2000;48:S84-S90.

38. Rosenfeld KE, Wenger NS, Kagawa-Singer M. End-of-life decision making: A qualitative study of elderly individuals. J Gen Intern Med 2000;15:620625 .

39. Roupie E, Santin A, Boulme R et al. Patients' preferences concerning medical information and surrogacy: Results of a prospective study in a French emergency department. Intensive Care Med 2000;26:52-56.

40. Searight HR, Gafford J. "It's like playing with your destiny": Bosnian immigrants' views of advance directives and end-of-life decision-making. J Immigr Health 2005; 7:195-203.

41. Sehgal A, Galbraith A, Chesney $M$ et al. How strictly do dialysis patients want their advance directives followed? JAMA 1992;267:59-63.

42. Shawler C, High DM, Moore KK et al. Surrogate decision making for hospitalized elders. J Gerontol Nurs 1992;18:5-11.

43. Sjokvist P, Nilstum T, Svantesson $M$ et al. Withdrawal of life supportwho should decide? Intensive Care Med 1999;25:949-954.

44. Sloan JP. Advance directives: Patient preferences in family practice. Can Fam Physician 1990;36:876-878.

45. Sulmasy DP, Hughes MT, Thompson RE et al. How would terminally ill patients have others make decisions for them in the event of decisional incapacity? A longitudinal study. J Am Geriatr Soc 2007;55:1981-1988.

46. Terry PB, Vettese M, Song J et al. End-of-life decision making: When patients and surrogates disagree. J Clin Ethics 1999;10:286-293.

47. Waters CM. Understanding and supporting African Americans' perspectives of end-of-life care planning and decision making. Qual Health Res 2001;11:383-398.

48. Waters CM. End-of-Life care directives among African Americans: Lessons learned-a need for community-centered discussion and education. J Community Health Nurs 2000;17:25-37.

49. Shalowitz D, Garrett-Mayer E, Wendler D. The accuracy of surrogate decision-makers: A systematic review. Arch Intern Med 2006;166:493-497.

50. Rid A, Wendler D. Can we improve medical treatment decision-making for incapacitated patients? Hastings Cent Rep 2010;40:36-45.

51. Davidson JE, Powers K, Hedayat KM et al. Clinical practice guidelines for support of the family in the patient-centered intensive care unit: American College of Critical Care Medicine Task Force 2004-2005. Crit Care Med 2007;35:605-622.

52. Thompson BT, Cox PN, Antonelli M et al. Challenges in end-of-life care in the ICU: Statement of the 5th International Consensus Conference in
Critical Care: Brussels, Belgium, April 2003: Executive summary. Crit Care Med 2004;32:1781-1784.

53. Uhlmann RF, Pearlman RA, Cain KC. Physicians' and spouses' predictions of elderly patients' resuscitation preferences. J Gerontol 1988;43:M115M121.

54. Fischer GS, Tuslky JA, Rose MR et al. Patient knowledge and physician predictions of treatment preferences after discussion of advance directives. J Gen Intern Med 1998;13:447-454.

55. Coppola KM, Ditto PH, Danks JH et al. Accuracy of primary care and hospital-based physicians' predictions of elderly outpatients' treatment preferences with and without advance directives. Arch Intern Med 2001;161:431-440.

56. Rid A, Wendler D. Use of a patient preference predictor to help make medical decisions for incapacitated patients. J Med Phil in press.

57. Rid A, Wendler D. Treatment decision making for incapacitated patients: Is development and use of a patient preference predictor feasible? J Med Phil in press.

58. Berger JT, DeRenzo EG, Schwartz J. Surrogate decision making: Reconciling ethical theory and clinical practice. Ann Intern Med 2008;149:48-53.

\section{APPENDIX}

\section{SEARCH TERMS}

The search terms were: Advance care planning [Medical Subject Headings] or advance directives [Medical Subject Headings] or advance directive adherence [Medical Subject Headings] or resuscitation orders [Medical Subject Headings] or withholding treatment [Medical Subject Headings] or treatment refusal [Medical Subject Headings] or Critical Care [Medical Subject Headings] or Intensive Care [Medical Subject Headings] or Life Support Care [Medical Subject Headings] or Palliative Care [Medical Subject Headings] or Terminal Care or resuscitation [Medical Subject Headings] or "end-of-life" [tw] AND Proxy [Medical Subject Headings] or legal guardians [Medical Subject Headings] or third-party consent [Medical Subject Headings] or family [major] or caregivers [Medical Subject Headings] or surrog* [tw] or mental competency [Medical Subject Headings] or "durable power of attorney" [tw] AND Choice* [Title] or prefer* [Title] or goal* [Title] or desire* [Title] or wish* [Title] or attitude* [Title] or values [Title] or communication [Medical Subject Headings] or decision-making [Medical Subject Headings]. 